\title{
A comparative study of ion diffusion during water imbibition in shale, sandstone and volcanic rock
}

\author{
Liu Yang ${ }^{\oplus *}$, Chenjiu Chen, Yifan Liu, Yuanhan Zheng \\ State Key Laboratory for Geomechanics and Deep Underground Engineering, China University of Mining and Technology (Beijing), \\ Beijing 100083, P. R. China
}

Keywords:

Ions diffusion

imbibition

clay minerals

fracturing fluid

Cited as:

Yang, L., Chen, C., Liu, Y., Zheng, Y. A comparative study of ion diffusion during water imbibition in shale, sandstone and volcanic rock. Capillarity, 2020, 3(2): 16-27, doi: 10.46690/capi.2020.02.01.

\begin{abstract}
:
The recovered fracturing fluid is generally high in salinity (close to $200 \mathrm{kppm}$ ), which is related to the diffusion of salt ions from shale reservoir to the fracturing fluid. However, it is not clear about the diffusion capacity of salt ions in different types. In this paper, the shale, tight volcanic and sandstone are selected as comparative study and a series of tests are carried out for the porosity, permeability and mineral composition. The results show that the shale immersing in fracturing fluid will cause ions dissolution and diffusion, which will increase the salinity of the fracturing fluid. The solution salinity increases rapidly in the early stage and gradually slows down in the later stage. The salinity of the fracturing fluid has a linear relationship with the square root of time, so the slope of the curve can be used as a characteristic parameter to evaluate the ion diffusion rate. The process of dissolution and diffusion of salt ions will induce the expansion of micro-cracks, increasing the contact area between the fracturing fluid and shale and enhancing the solution salinity. The ion diffusion rate is positively related with the content of clay minerals and carbonate. The soluble ions include mainly $\mathrm{SO}_{4}^{2-}, \mathrm{Ca}^{2+}, \mathrm{Na}^{+}$and $\mathrm{K}^{+}$. The $\mathrm{Na}^{+} / \mathrm{Cl}^{-}$ratio is closely related to the content of clay minerals and carbonate minerals. It has a positive correlation with content of illite and chlorite, and a negative correlation with carbonate minerals, suggesting $\mathrm{NaCl}$ source from illite and chlorite. This study is significant for understanding the salinity characteristics of recovered fracturing fluid and evaluating the fracture network shape.
\end{abstract}

\section{Introduction}

In shale reservoirs, fracture networks are induced by largescale injection of fracturing fluid into the formation, achieving volumetric fracturing stimulation of the formation and thereby increasing shale gas production (Cheng et al., 2015). Field experience shows that the concentration of the flowback fluid is much higher than that of the injected fracturing fluid (even more than 100 times). It relates to shut-in time, contact area and the salinity difference between shale and fracturing fluid (Fakcharoenphol et al., 2014). Many research results attribute this phenomenon to the diffusion of shale reservoir ions into the fracturing fluid, thus increasing the concentration of the flowback fluid (Gdanski et al., 2010). However, the diffusion capacity of ions and its influencing factors are still unclear. The diffusion characteristics of different types ions need to be further studied.

The main motion modes of ions movement in shale reservoirs include convection and diffusion to fracturing fluid. The ion convection depends on obvious fluid movement behavior
(Haluszczak et al., 2013). During the fracturing operations, the fracturing fluid will flow quickly on the wall of artificial fracture network, and the influence of convection effect is significant (Mahabadi et al., 2016). Therefore, the ions concentration in the fracturing fluid increases rapidly, resulting in high salinity characteristics of the recovered fluid. On the contrary, the flow velocity of fracturing fluid is slow within the matrix pores, which does not meet the requirements of ion convection effect (Tao et al., 2017). The main mode of ion movement is diffusion in matrix pores ( $\mathrm{Li}$ et al., 2016), following the Fick's law. Ion motion is also related to temperature and fluid viscosity. The temperature is positively correlated with the rate of ion movement. As the temperature increases, the rate of ion movement increases (Sun et al., 2018). The increase in the viscosity of the fluid will cause the fluid to move at a lower speed, resulting in the inhibition of convection effect.

There are many factors affecting ion diffusion, and the mechanism is more complicated. The ion diffusion rate of shale reservoirs is related to the properties of the shale itself,

\footnotetext{
\begin{tabular}{c|} 
Yandy \\
Scientific
\end{tabular}

${ }^{*}$ Corresponding author.

E-mail address: shidayangliu@cumtb.edu.cn (L. Yang); 765508040@qq.com (C. Chen); nevermind_crisis@sina.com (Y. Liu);

1292708265@qq.com (Y. Zheng).

2652-3310 (c) The Author(s) 2020.

Received May 13, 2020; revised May 27, 2020; accepted May 28, 2020; available online June 1, 2020.
} 
Yang, L., et al. Capillarity 2020, 3(2): 16-27

Table 1. Shale properties in this study.

\begin{tabular}{llll}
\hline Label & Formation & Lithology & Source \\
\hline L1 & Longmaxi & Shale & Sichuan Basin \\
L2 & Longmaxi & Shale & Sichuan Basin \\
N1 & Niutitang & Shale & Sichuan Basin \\
N2 & Niutitang & Shale & Sichuan Basin \\
C1 & Chang-7 & Shale & Ordos Basin \\
G1 & Ganchaigou & Shale & Jungar Basin \\
Y1 & Yingcheng & Volcanic rock & Songliao Basin \\
Y2 & Yingcheng & Volcanic rock & Songliao Basin \\
Y3 & Yingcheng & Volcanic rock & Songliao Basin \\
S1 & Shihezi & Tight sandstone & Ordos Basin \\
\hline
\end{tabular}

Table 2. Physical characteristics of the sample.

\begin{tabular}{llllll}
\hline Sample & Surface area $\left(\mathrm{cm}^{2}\right)$ & Height $(\mathrm{cm})$ & Porosity $(\%)$ & Permeability $(\mathrm{mD})$ & Ion diffusion rate $\left(\mu \mathrm{S} / \mathrm{cm}^{\prime} /\left(\mathrm{cm}^{2} \cdot \mathrm{h}^{0.5}\right)\right.$ \\
\hline L1 & 14.33 & 1.2 & 2.3 & 0.0032 & 0.5235 \\
L2 & 53.38 & 0.8 & 2.9 & 0.0024 & 0.3816 \\
N1 & 45.75 & 0.8 & 3.4 & 0.0026 & 0.1841 \\
N2 & 43.00 & 0.72 & 1.8 & 0.0021 & 0.1319 \\
C1 & 19.56 & 1.2 & 1.3 & 0.0008 & 0.3709 \\
G1 & 11.19 & 0.8 & 3.4 & 0.057 & 0.5111 \\
Y1 & 8.83 & 0.5 & 6.8 & 0.079 & 0.18 \\
Y2 & 8.05 & 0.4 & 8.3 & 0.025 & 0.1449 \\
Y3 & 8.05 & 0.4 & 3.2 & 0.0057 & 0.0922 \\
S1 & 19.04 & 1.8 & 7.6 & 0.12 & 0.3833 \\
\hline
\end{tabular}

such as porosity, permeability, bedding clay mineral content and type, and also to the properties of the fluid, such as viscosity, composition, etc (Meng et al., 2016). Among them, the greater the difference between shale and fluid salinity and the faster the ion diffusion rate. During the flow of fracturing fluid, it will result in fracturing fluid imbibition, and imbibition rate will greatly affect the ion diffusion in the shale reservoir. Therefore, the factors that affect imbibition can also affect the ion diffusion of shale reservoirs (Li et al., 2019), such as surface tension, wetting angle, pore size, etc. According to the mechanism of chloride ion diffusion in concrete structures, factors such as clay mineral hydration, micro-heterogeneity, and salt ions adsorption also have an effect on shale ion movement (Cai et al., 2020a). In addition, the diffusion rate also relates to the different types of salt ions.

The theory of water and salt migration has received attention and application in many fields, such as secondary soil salinization, migration of pollutants in strata, and seawater intrusion in coastal areas, etc (Ghanbari et al., 2013; Cai et al., $2020 \mathrm{~b}$ ). However, there are few studies on salinity changes of recovered fracturing fluid. It is not clear about the diffusion capacity of salt ions in different types. In addition, the characteristics of shale itself are relatively complex, which makes it difficult to directly apply the water-salt migration theory to analyze the problem of shale ion diffusion. Therefore, this study selected shale samples for ion diffusion experiments, and then compared them with tight sandstone and volcanic rocks to study the characteristics and influencing factors of salt ion diffusion.

\section{Materials and methods}

\subsection{Samples characterization}

The shale samples taken in this experiment came from the Sichuan Basin, Ordos Basin and Junggar Basin. The volcanic rock samples were taken from the Songliao Basin, and the tight sandstones were taken from the Ordos Basin, as shown in Table 1. The Longmaxi and Niutitang Formation in the Sichuan Basin of China are mainly marine sediments. The shale formations in the Ordos Basin and the Junggar Basin is continental sediments. The volcanic rock formation is mainly taken from the Yingcheng Formation in the Songliao Basin. The tight sandstone formation is mainly taken from Shihezi formation in the Ordos Basin. The rock samples of different lithologies are used for comparative tests.

The physical parameters of the samples are shown in Table 2. The porosity is determined by helium porosimeter, and the permeability is measured by ultra-low permeability 
Table 3. Sample mineral composition information.

\begin{tabular}{|c|c|c|c|c|c|c|c|c|c|c|}
\hline \multirow[b]{2}{*}{ Label } & \multicolumn{5}{|c|}{ Relative abundance } & \multirow[b]{2}{*}{ Clay } & \multirow[b]{2}{*}{ Quartz } & \multirow[b]{2}{*}{ Feldspar $^{b}$} & \multirow[b]{2}{*}{ Carbonates $^{c}$} & \multirow[b]{2}{*}{ Pyrite } \\
\hline & Smectite & Illite & $\mathrm{I} / \mathrm{S}^{a}$ & Chlorite & Kaolinite & & & & & \\
\hline L1 & 7.3 & 8.5 & 71.6 & 9.5 & 3.1 & 29.8 & 36.3 & 5.4 & 24.5 & 4.0 \\
\hline L2 & 2.3 & 14.6 & 63.2 & 15.0 & 4.9 & 27.4 & 35.5 & 8.5 & 21.4 & 7.3 \\
\hline N1 & 4.0 & 6.6 & 68.5 & 18.6 & 2.3 & 21.2 & 39.1 & 20.9 & 15.7 & 3.1 \\
\hline $\mathrm{N} 2$ & 2.1 & 10.6 & 58.6 & 8.7 & 20.1 & 19.4 & 28.7 & 37.7 & 11.4 & 2.8 \\
\hline $\mathrm{C} 1$ & 0 & 33.5 & 41.5 & 16.9 & 8.1 & 33.6 & 35.1 & 11.5 & 8.2 & 12.1 \\
\hline G1 & 0 & 15.7 & 35.3 & 29.6 & 19.4 & 48.5 & 31.4 & 1.4 & 18.7 & 0 \\
\hline Y1 & 0 & 6 & 55.8 & 38 & 0 & 23.4 & 45.5 & 26.6 & 4.5 & 0 \\
\hline Y2 & 0 & 10.8 & 62.0 & 2 & 25.2 & 19.8 & 42.7 & 36.2 & 1.3 & 0 \\
\hline Y3 & 0 & 17.9 & 71.5 & 10.5 & 0 & 17.7 & 48.5 & 30.3 & 3.5 & 0 \\
\hline $\mathrm{S} 1$ & 0 & 21.2 & 75.4 & 0 & 3.4 & 19.1 & 35.2 & 18.6 & 27.1 & 0 \\
\hline
\end{tabular}

instrument. The porosity and permeability instruments are made in Hua'an Scientific Instrument Co. Ltd in China. The shale porosity is between $1.3 \%$ and $3.4 \%$, and the average porosity is $2.52 \%$. The permeability is between $0.0008 \mathrm{md}$ and $0.057 \mathrm{md}$, and the average permeability is $0.0114 \mathrm{md}$. The porosity of the volcanic rock samples is $3.2 \% \sim 8.3 \%$ and the average porosity is $6.1 \%$. The permeability is $0.0057 \sim 0.079$ $\mathrm{md}$, and the average permeability is $0.037 \mathrm{md}$. The tight sandstone has a porosity of $7.6 \%$ and a permeability of 0.12 md. The porosity of the volcanic rock is relatively close to that of tight sandstone, which is much larger than that of the shale.

The mineral composition of the sample is shown in Table 3. The results are determined by X-ray diffraction mineral analysis method. For the shale formation, the main minerals are quartz and clay minerals. The quartz content is $28.7 \% \sim 39.1 \%$, and the clay content is $19.4 \% \sim 48.5 \%$. For tight volcanic rock and sandstone, the quartz content is $35.2 \% \sim 48.5 \%$, and the clay content is $17.7 \% \sim 23.4 \%$. The clay minerals of shale formation are much larger than that of tight volcanic rock and sandstone. In addition, the clay minerals are mainly composed of illite and I/S (illite/smectite mixed-layer) minerals. The content of smectite is lower than $10 \%$ in shale formation, and the content of smectite is close to 0 in tight volcanic rock

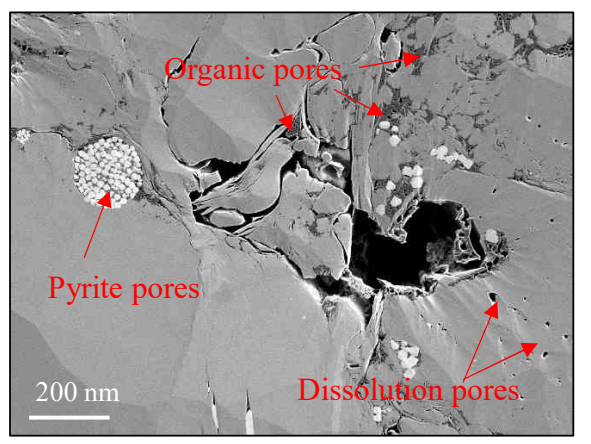

and sandstone formation. The shale has the stronger water sensitiveness than tight volcanic rock and sandstone.

Fig. 1 shows the SEM observation results of shale sample (L1) and volcanic rock sample (Y3). It can be seen that micronano pores and organic matter are developed in shale and volcanic rock. Shale develops micro-cracks and different types of pores, such as pyrite pores, organic pores and dissolution pores. Micro-cracks can connect different types of pores and can be used as an important channel for fluid migration. It should be pointed out that most organic pores of volcanic rocks are not developed. From the micro-scale, compared with volcanic rocks, shale reservoirs are more conducive to the occurrence and exploitation of oil and gas.

\subsection{Experimental procedures}

The conductivity meter (Mettler-Toledo) is composed of an electrode, a movable support and a host (Fig. 2). The electrode diameter is about $1 \mathrm{~cm}$ and the measurement distance to the bottom is set $4 \mathrm{~cm}$ (Yang et al., 2017a). The measuring range of conductivity is $0.01 \sim 500 \mu \mathrm{S} / \mathrm{cm}$, aand that of total dissolved solid is $0.01 \mathrm{mg} / \mathrm{L} \sim 300 \mathrm{~g} / \mathrm{L}$. The conductivity meter forms a conductive loop through the ion and the conductivity meter, thereby measuring the change in conductivity (Fig. 3).

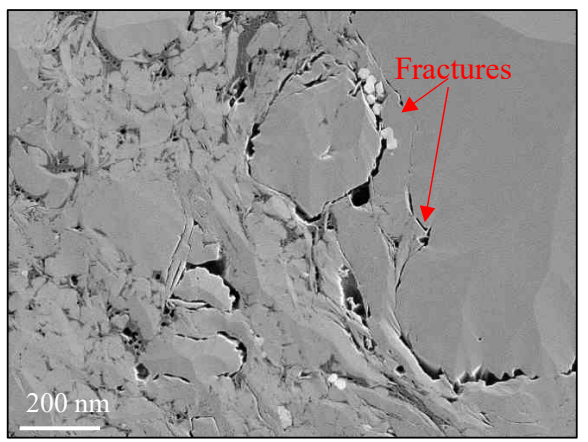



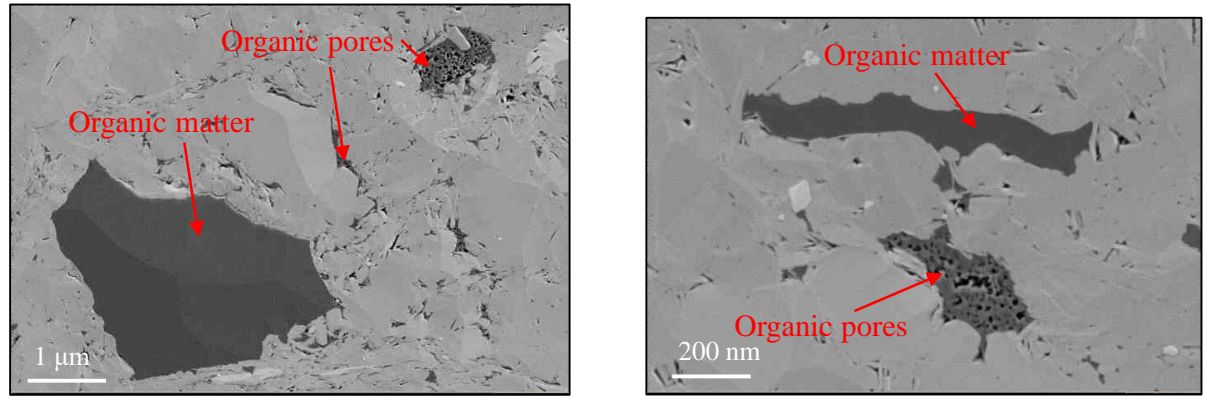

(b)

Fig. 1. SEM picture of different samples: (a) L1 sample and (b) Y3 sample.

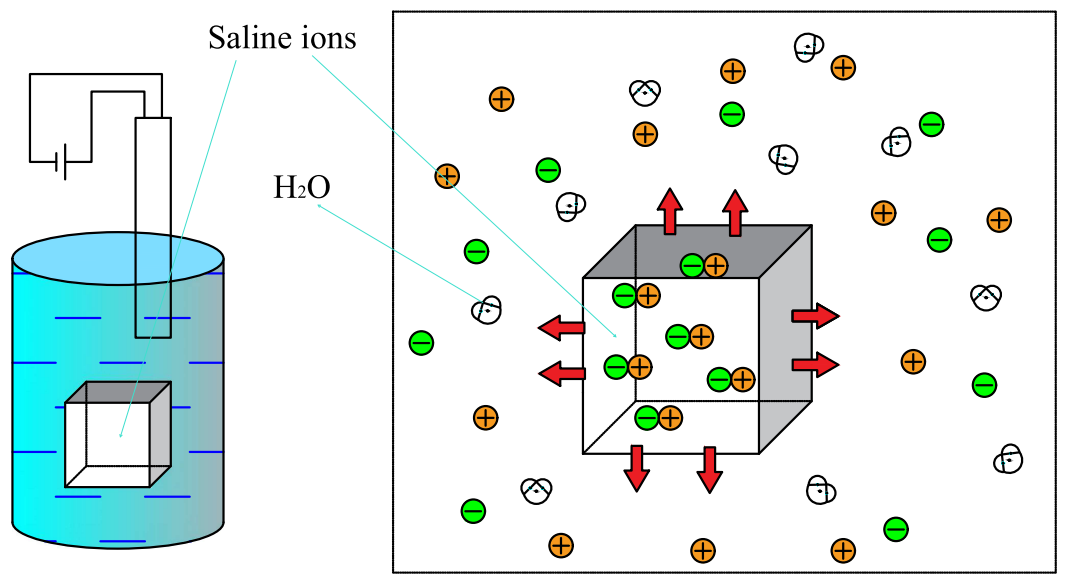

Fig. 3. The schematic diagram of disintegration experiment.

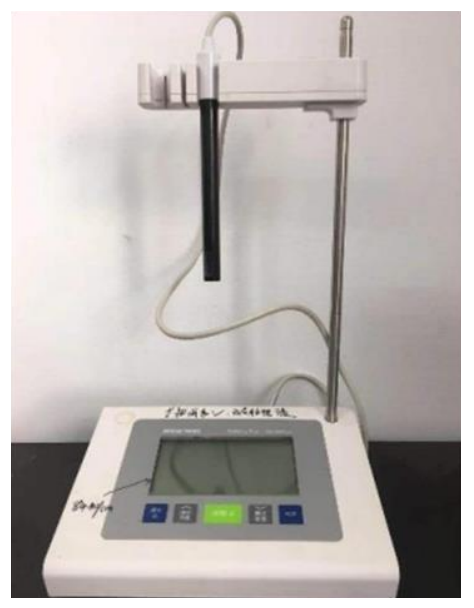

Fig. 2. The conductivity meter.

The higher the solubility of ions in the solution, the higher the conductivity. The conductivity meter ions dissolve and diffuse into the water, causing solution salinity to rise gradually.

Experimental materials include a $250 \mathrm{ml}$ beaker, $100 \mathrm{ml}$ measuring cylinder, plastic film, rubber band, conductivity meter, electronic balance, tweezers, vernier caliper, drying oven, measuring test paper, knife and thermometer. The experimental procedures are as follows:

1) Cut the sample into a cylindrical shape with a cutting machine, measure the diameter and length of the sample with a vernier caliper, and weigh the sample with an electronic balance. Dry the sample at $105{ }^{\circ} \mathrm{C}$ until the sample mass no longer changes.

2) Pour $200 \mathrm{ml}$ of distilled water into 10 beakers and use a conductivity meter to measure the conductivity of the distilled water. After completion, the average conductivity of the distilled water is obtained and used as comparative data for subsequent experiments. Place 10 sets of samples in water for a long enough time.

3) Use a glass rod to stir the water to distribute the concentration evenly. Immerse the conductive electrode in water to measure the conductivity, and record the changes of the sample surface by taking pictures. After the test, the beaker is sealed with plastic film and rubber band.

4) Repeat step 3 to determine the conductivity change during the soak time. Plot the curves of conductivity change with the square root of time.

\section{Experimental results}

\subsection{Observations during ion diffusion experiments}

Table 4 shows the appearance of four shale samples (C1, $\mathrm{S} 1, \mathrm{~L} 2$, and L1). The soaking process may last for about 
Table 4. Sample change before and after the experiments.

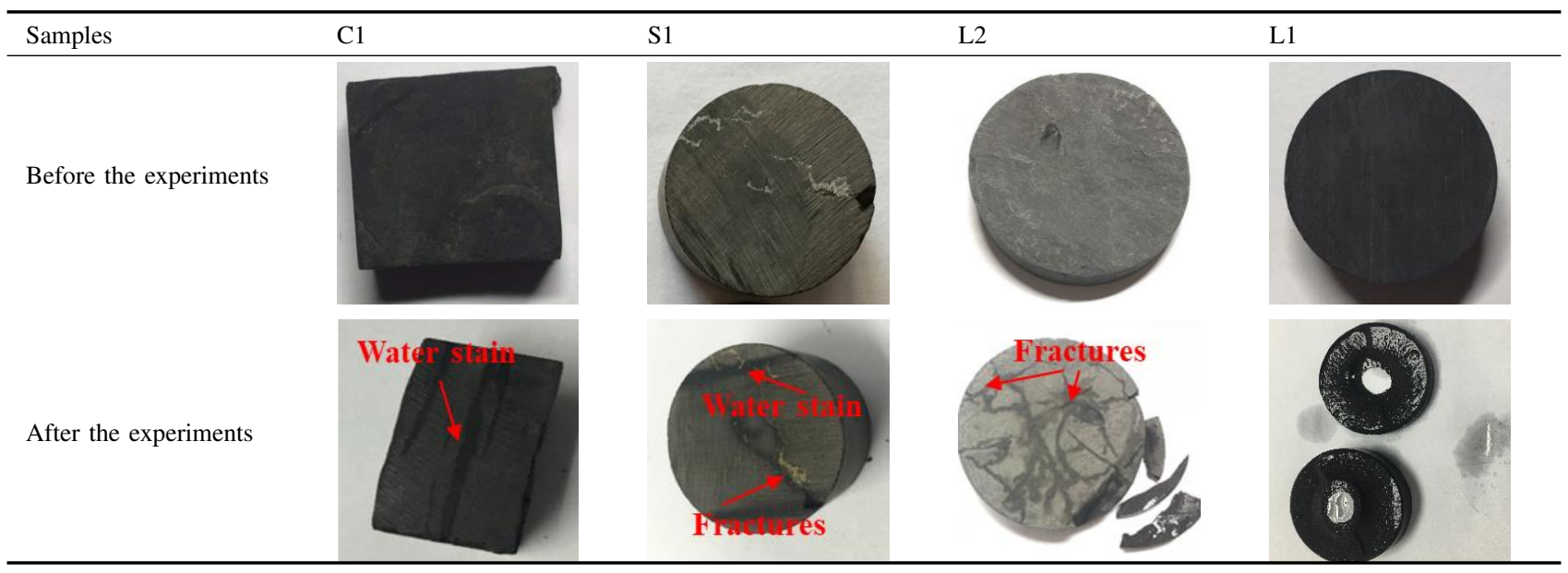

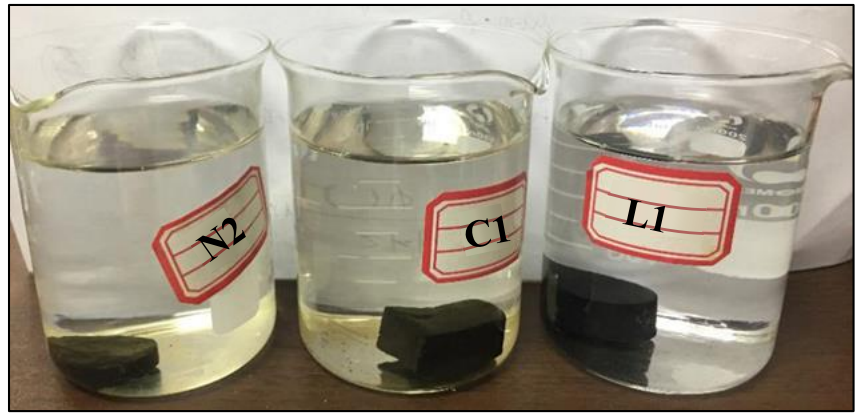

(a) $\mathrm{N} 2$

(b) $\mathrm{C} 1$

(c) L1

Fig. 4. The solution color comparison: (a) $\mathrm{N} 2$ sample and (b) $\mathrm{C} 1$ sample and (c) L1 sample.

2000 3000 hrs. Sufficient immersion for a long time makes the sample have more stable cracks or traces, and the ion concentration distribution in the solution also tends to be stable. After the shale is in contact with the solution, cracks of different sizes appear on the surface. The generated cracks of different samples are also different in shape. The cracks may be caused by the swelling of clay minerals in the shale. Unlike the previous sample solution, the L1 sample solution is colorless and transparent, and the color of the two sample solutions (C1 and N2) is brownish (Fig. 4). According to the experimental results of Hutcheon in 1998, the yellowish color may be caused by the unstable oxidation of ferrous ions in the air to ferric iron. The chemical reaction equation is as follows:

$$
\begin{gathered}
\mathrm{FeS}_{2}+8 \mathrm{H}_{2} \mathrm{O}=\mathrm{Fe}^{2+}+2 \mathrm{SO}_{4}^{2-}+16 \mathrm{H}^{+}+14 \mathrm{e}^{-} \\
4 \mathrm{Fe}^{2+}+\mathrm{O}_{2}+4 \mathrm{H}^{+}=4 \mathrm{Fe}^{3+}+2 \mathrm{H}_{2} \mathrm{O}
\end{gathered}
$$

There is no obvious fractures in the surface of $\mathrm{C} 1$ sample before and after immersion. After the immersion, there is a vertical water mark on the surface. The $\mathrm{S} 1$ sample is similar to the $\mathrm{C} 1$ sample. The surface watermark is less, and the overall change is not obvious. The only difference is that S1 sample has two symmetric watermarks, and there are two sides of the watermark. Compared with the S1 and C1 samples, the L2 sample shows large cracks and breakage after immersion, and there are many surface cracks. There is a wetting phenomenon around the lines. If the large cracks generated on the sample surface are connected with the micro cracks, the porosity and permeability of the shale sample will increase significantly.

\subsection{Characteristics of ion diffusion experiments}

The ion diffusion experiments are conducted on 10 samples. For the different samples, the Fig. 5 shows the curves of the solution conductivity with time. The conductivity of distilled water is about $2.0 \mu \mathrm{S} / \mathrm{cm}$, which will not increase with time. Therefore, it has little effect on the experiment, and can be ignored. The general trend of the conductivity curve is basically the same. As the immersion time increases, the conductivity in the solution gradually increases. It shows that a large amount of salt ions in the rock dissolve and diffuse into the water, which improves the water salinity. The diffusion process of shale ions can be roughly divided into two stages (rapid diffusion stage and slow diffusion stage). During the rapid diffusion stage, the conductivity increases significantly. After reaching about $500 \mathrm{~h}$, it enters a slow diffusion stage, 


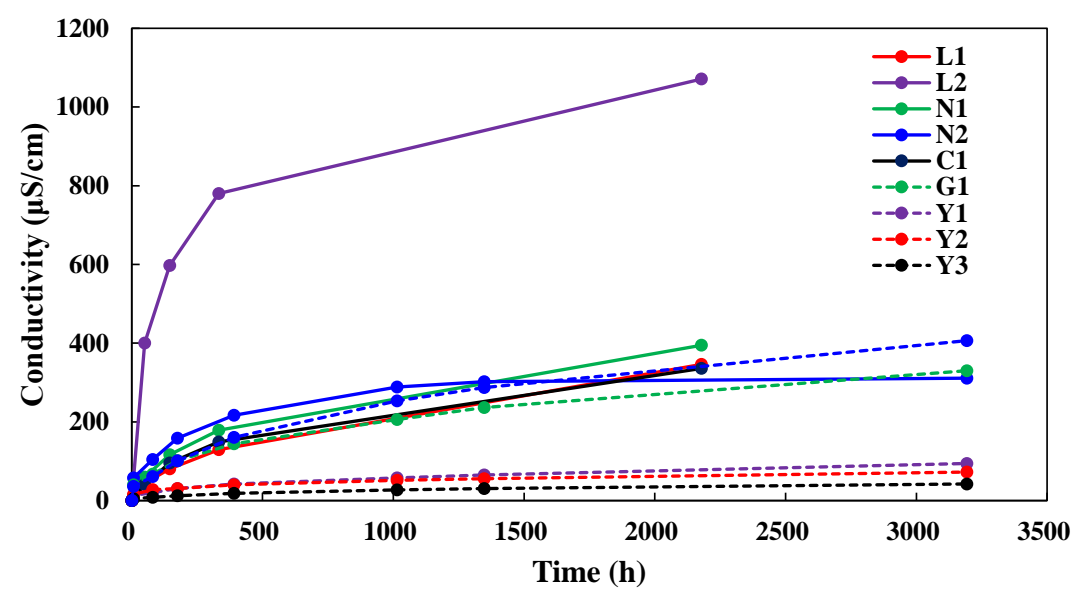

Fig. 5. The relationship between conductivity and soaking time.

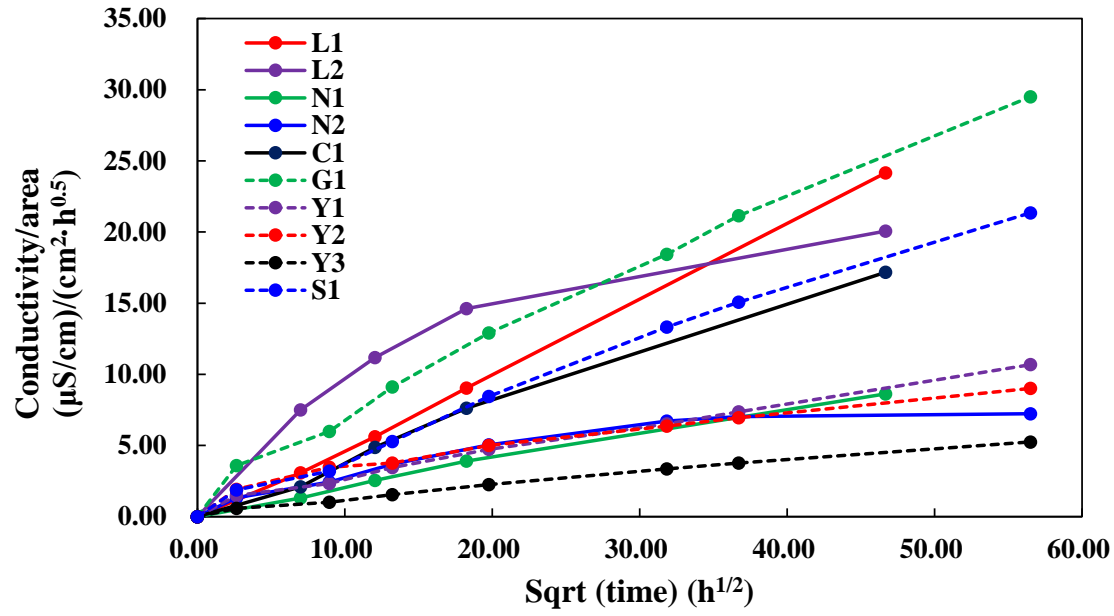

Fig. 6. The relationship between conductivity and square root of soaking time.

and the growth rate of electrical conductivity slows down. The curve of the conductivity change with time has a more obvious decline. It tends to be gentle, and the increase rate is not large. Electrolytes, such as salts, generate ions when ionized in water, causing the conductivity to rise rapidly, and soluble ions in the pore walls dissolve into the solution. As the electrolyte on the pore wall ionizes, ions enter the solution, leaving behind non-electrolyte compounds that are poorly soluble in water. Therefore, the chemical reaction with water weakens or the dissolved substances decrease, and the reaction area gradually decreases on the pore wall. The ions dissolution rate tends to be gentle inside the solution. When the compound on the pore wall hardly ionizes or dissolves with water, the conductivity in the solution no longer changes with time. At this time, the conductivity reaches the maximum value within a period of time. Compared with the conductivity of distilled water, the solution conductivity of samples has obviously changed, which proves the correctness of the conclusion that the ions in the sample will move into the solution.

Fig. 6 is the curves of conductivity/area vs. the square root of time. It can be seen that the conductivity curve is approximately linear. The slope of the conductivity curve can be used as a characteristic parameter of shale ion diffusion, indicating the diffusion rate of ions. The greater the slope, the greater the ion diffusion rate. The ion diffusion rate of the L2 sample is large, which is related to the initiation and propagation of microcracks. The existence of micro-cracks in the early stage increases the contact area between shale and water, making the sample have a higher ion diffusion rate. In addition, the curves of different samples are not strictly straight lines, which is related to the swelling of clay minerals by water absorption. The expansion of clay minerals leads to continuous changes in the pore structure. It results in the continuous change of the ion diffusion path, which in turn affects the ion diffusion rate.

Fig. 7 presents the schematic of conductivity curves. The change curves of the unit surface area conductivity with the square root of time can be divided into three parts: linear fast diffusion stage, nonlinear transition stage, and linear slow diffusion stage. During the linear rapid diffusion phase, free water enters the shale pores. The soluble salts on the pore walls of the shale ionize with water and generate large amounts of 


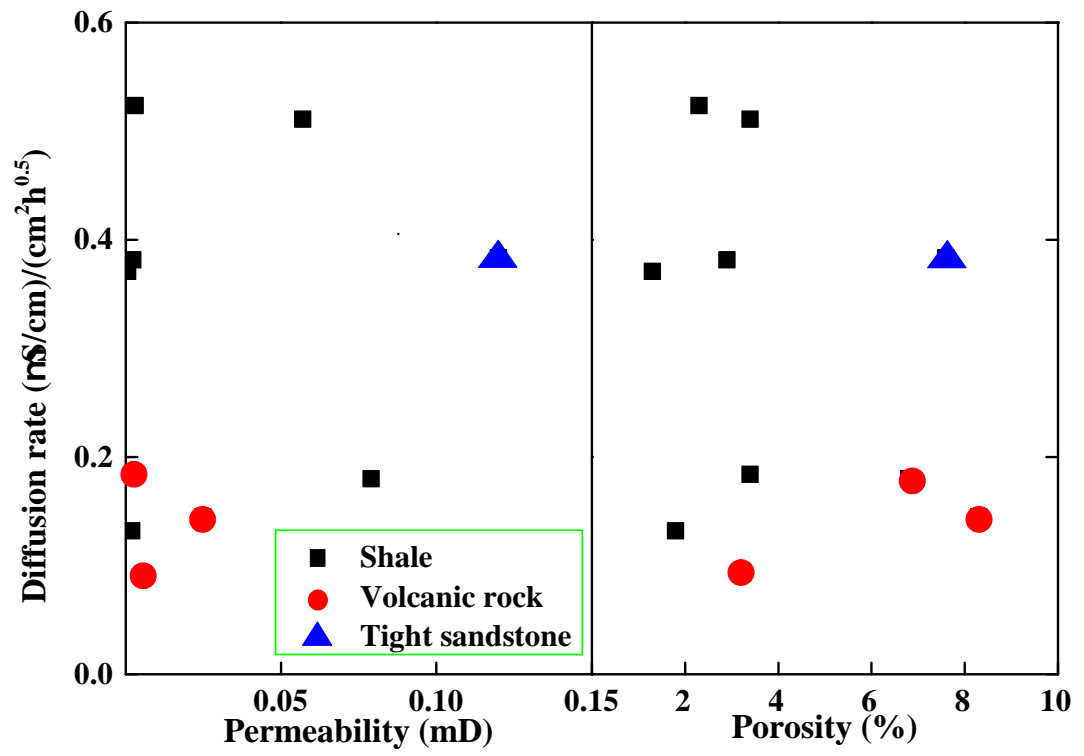

Fig. 8. Effects of permeability (left) and porosity (right) on ion diffusion rate.

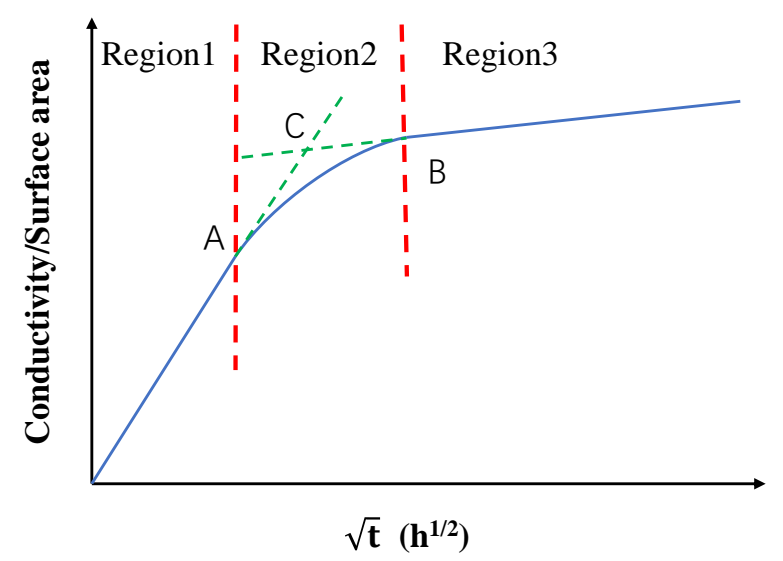

Fig. 7. The schematic of conductivity curves.

ions. These ions enter the solution, causing the solution conductivity to rise rapidly. In the non-linear transition stage, as the pore water saturation of the shale sample increases, the water self-priming effect caused by capillary pressure begins to weaken. And the solubility difference between pore wall and the solution decreases, and the diffusion rate of ions slows. In the linear slow diffusion stage, the difference between the ionic solubility in the pores and the ionic solubility in the solution is further reduced. On the pore wall, the chemical substances that can react with water or the dissolved substances decrease, and the reaction area gradually decreases. The solubility growth of ions in the solution tends to be gentle, and the conductivity does changes with the square root of time.

\subsection{Factors influencing ion diffusion \\ 3.3.1 Effects of permeability and porosity}

According to the calculation results of Yang et al. (2017b), the porosity is positively related to the specific surface area.
The higher the porosity, the larger the specific surface area. Ionizable salts on the walls of the well may come into contact with water. It contribute to ion diffusion from the matrix pores to water. This causes the solution conductivity to increase. The permeability increases the advancing speed of the leading edge of water imbibition, but reduces the specific surface area and decreases the ion diffusion rate. Fig. 8 shows the effects of porosity and permeability on ion diffusion rate. The ion diffusion rate generally ranges from $0.09(\mu \mathrm{S} / \mathrm{cm}) /\left(\mathrm{cm}^{2} \cdot \mathrm{h}^{0.5}\right)$ to $0.55(\mu \mathrm{S} / \mathrm{cm}) /\left(\mathrm{cm}^{2} \cdot \mathrm{h}^{0.5}\right)$. No obvious relationship is found between ion diffusion rate and porosity-permeability. This is related to the strong heterogeneity of shale, and it is difficult to reflect the real results based on a few experiments.

\subsubsection{Effects of clay minerals}

The mineral content may also have an effect on the ion diffusion rate. The effects of clay mineral, carbonate, quartz, illite, chlorite, and I/S content are analyzed. The results are shown in Fig. 9. As the clay content increases, the ion diffusion rate increases. Clay minerals have a large specific surface area and are rich in soluble salt minerals (Yang et al., 2017b). Water enters into the clay crystal layers, causing the clay minerals to swell and releasing large amounts of salt ions. It increases the ion diffusion rate. The carbonate mineral content is positively correlated with the ion diffusion rate. Carbonate is generally a compound that is slightly soluble in water, so it has little effect on the ion diffusion rate. However, the water generally dissolves a certain concentration of carbon dioxide to form carbonic acid. The solution with low $\mathrm{pH}$ value can dissolve minerals such as calcite, thereby increasing the rate of ion diffusion. The quartz mineral content is inversely correlated with the ion diffusion rate. The quartz mineral itself does not dissolve and has no effect on the ion diffusion rate. But high quartz mineral content means low clay mineral content and low carbonate mineral content. Therefore, the high quartz mineral content reduces the ion diffusion rate. 


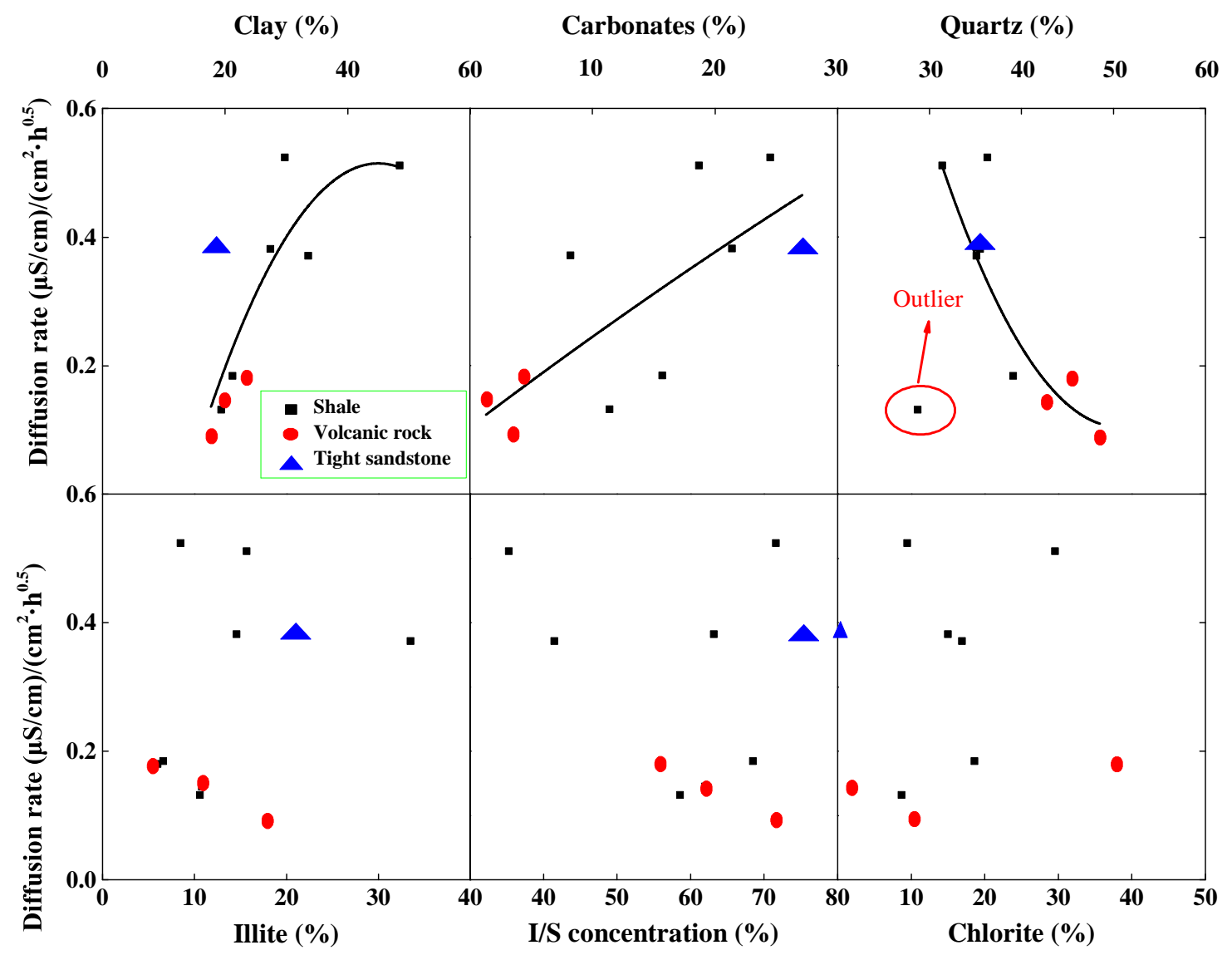

Fig. 9. Effects of mineral composition on ion diffusion rate.

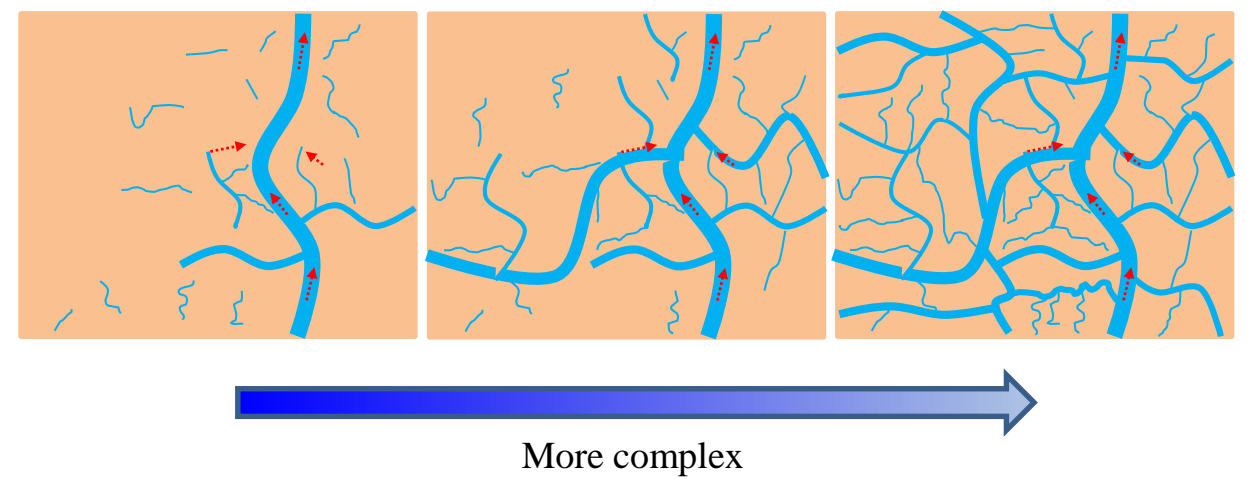

Fig. 10. Schematic diagram of crack changes.

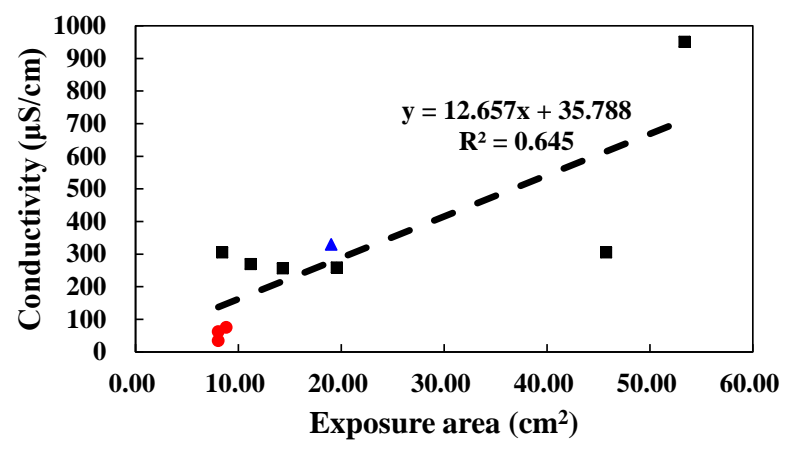

Fig. 11. Effects of exposure area on solution conductivity.
According to the results in Fig. 9, the type of clay mineral has little effect on the ion diffusion rate. The contents of illite, $\mathrm{I} / \mathrm{S}$ and chlorite have no significant effect on the ion diffusion rate. According to Yang et al. (2017a), I/S minerals have a great influence on the ion diffusion rate. As the I/S mineral content increases, the ion diffusion rate increases significantly. The I/S mineral has the characteristics of high specific surface area, and a large amount of salt ions are attached inside, which increases the ion diffusion rate. However, no similar phenomenon is found in the experiments in this paper, which can be explained by the strong heterogeneity of the shale itself. 


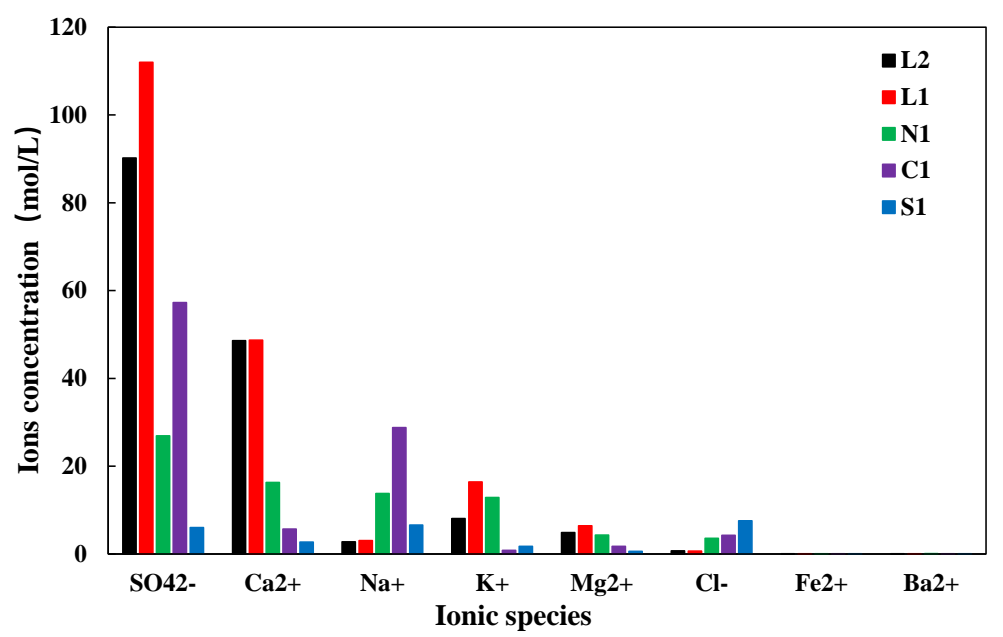

Fig. 12. The ions concentration and type in different formations.

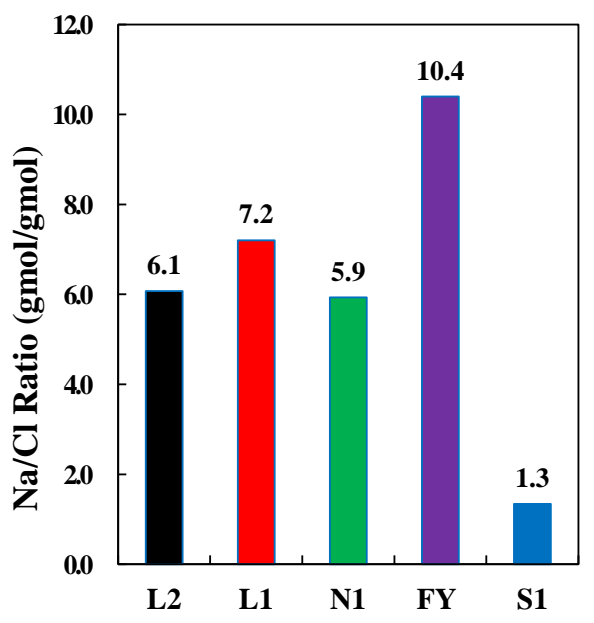

(a)

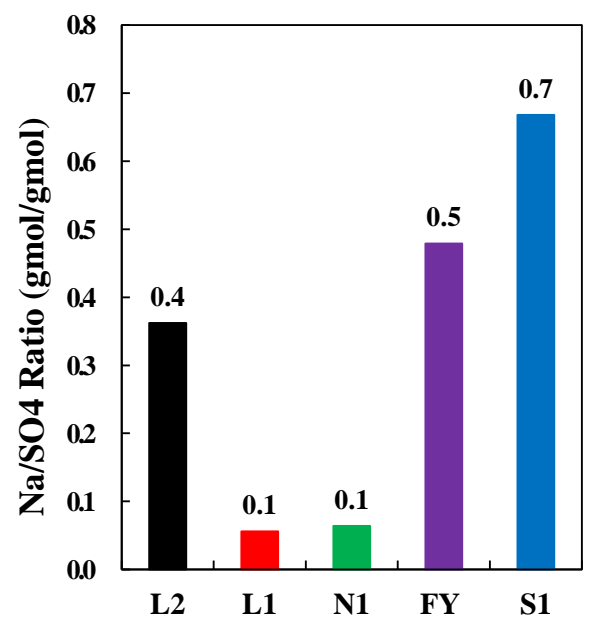

(b)

Fig. 13. The $\mathrm{Na}^{+} / \mathrm{Cl}^{-}$and $\mathrm{Na}^{+} / \mathrm{SO}_{4}^{2-}$ ratio in different formations: (a) $\mathrm{Na}^{+} / \mathrm{Cl}^{-}$and (b) $\mathrm{Na}^{+} / \mathrm{SO}_{4}^{2-}$.

\subsubsection{Effects of exposure area}

Fig. 11 shows the relationship between the solution conductivity and the exposed area at $2000 \mathrm{~h}$. It can be seen that they have a strong correlation. The larger the exposed area, the faster the solution conductivity rises. The high exposed area means that more salt-attached surfaces can come into contact with the solution, which can significantly increase the salinity of the solution. Therefore, the higher complexity of the artificial fracture corresponds to the larger contact area and higher salinity of the flow-back fluid. It can be seen that the salinity of the flow-back fluid is an important sign of the artificial fractures complexity (Fig. 10).

\subsection{Effects of ions type}

After the experiment, the plasma mass spectrometer is used to analyze the different solution ion types. Fig. 12 shows the ions concentration and type in different formations. It can be seen that the L2, L1 and N1 samples have the most abundant calcium and sulfate ions. It can be explained by a large amount of I/S minerals. The I/S mixed layer is often rich in $\mathrm{Ca}^{2+}$ and $\mathrm{SO}_{4}^{2-}$, so the concentration of sulfate and calcium ions in the solution is much higher than that of other groups. The $\mathrm{C} 1$ rock solution is rich in sodium ions, which may be sodium-rich minerals in the rock. The dissolution of minerals in the formation may be the main source of several ions. Different types of minerals are dissolved by the water absorbed into the pores, and gradually diffuse into the water under the effect of the concentration difference, which improves the concentration of different ions. The solubility of different minerals is different, resulting in different concentrations of different types ions.

According to the Surin principle of water type, $\mathrm{Na}^{+} / \mathrm{Cl}^{-}>1$ and $\left(\mathrm{Na}^{+}\right)-\left(\mathrm{Cl}^{-}\right) / \mathrm{SO}_{4}^{2-}<1$ in shale and volcanic samples indicates that the formation water type is $\mathrm{Na}_{2} \mathrm{SO}_{4}$ type. And the $\mathrm{Na}^{+} / \mathrm{Cl}^{-}<1$, and $\left(\mathrm{Cl}^{-}\right)-\left(\mathrm{Na}^{+}\right) / \mathrm{Mg}^{2+}<1$ in tight sandstone samples indicates that the formation water type is $\mathrm{CaCl}_{2}$ type. From the above analysis, it can be concluded that the tight sandstone sample formation has a good oil and gas storage 


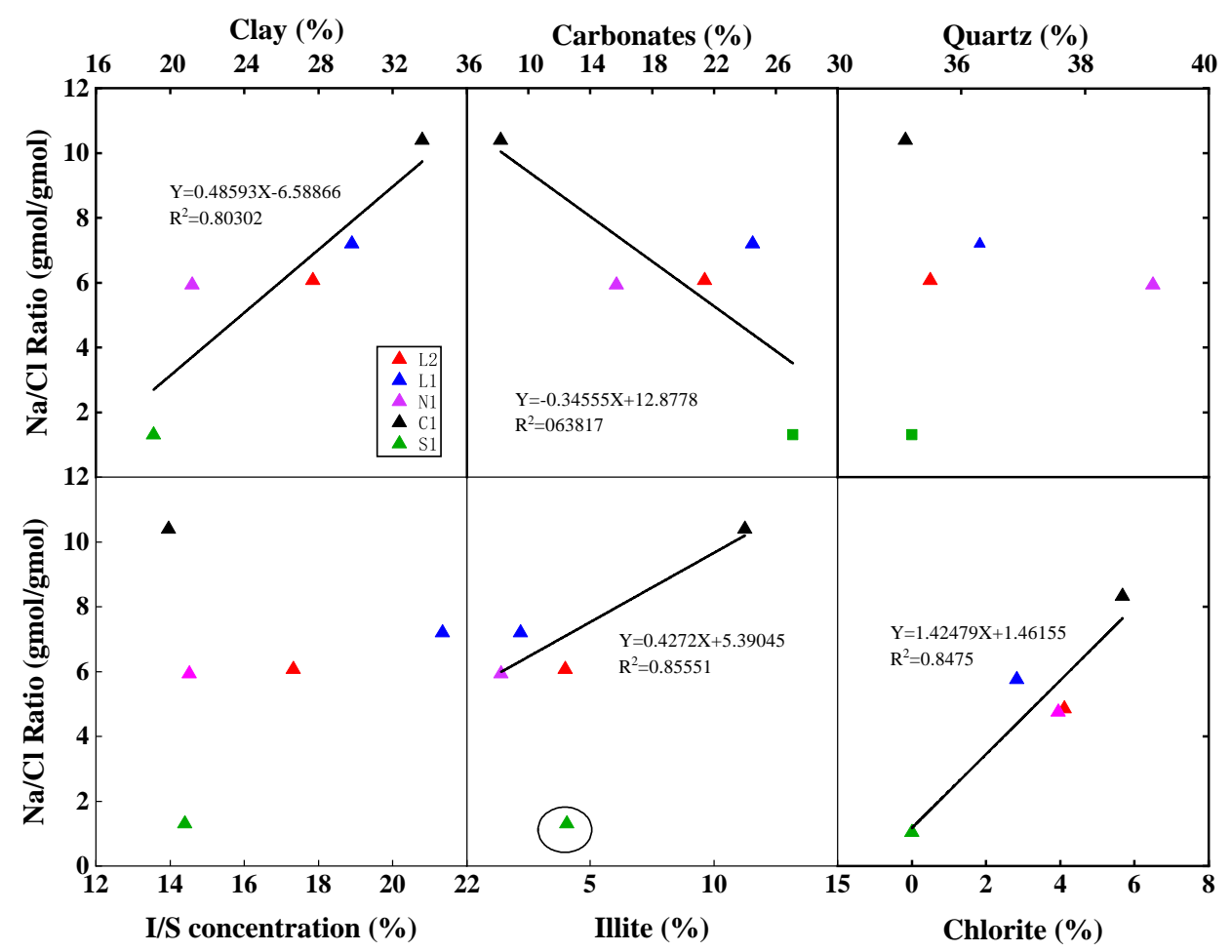

Fig. 14. Effects of mineral composition on $\mathrm{Na}^{+} / \mathrm{Cl}^{-}$ratio.

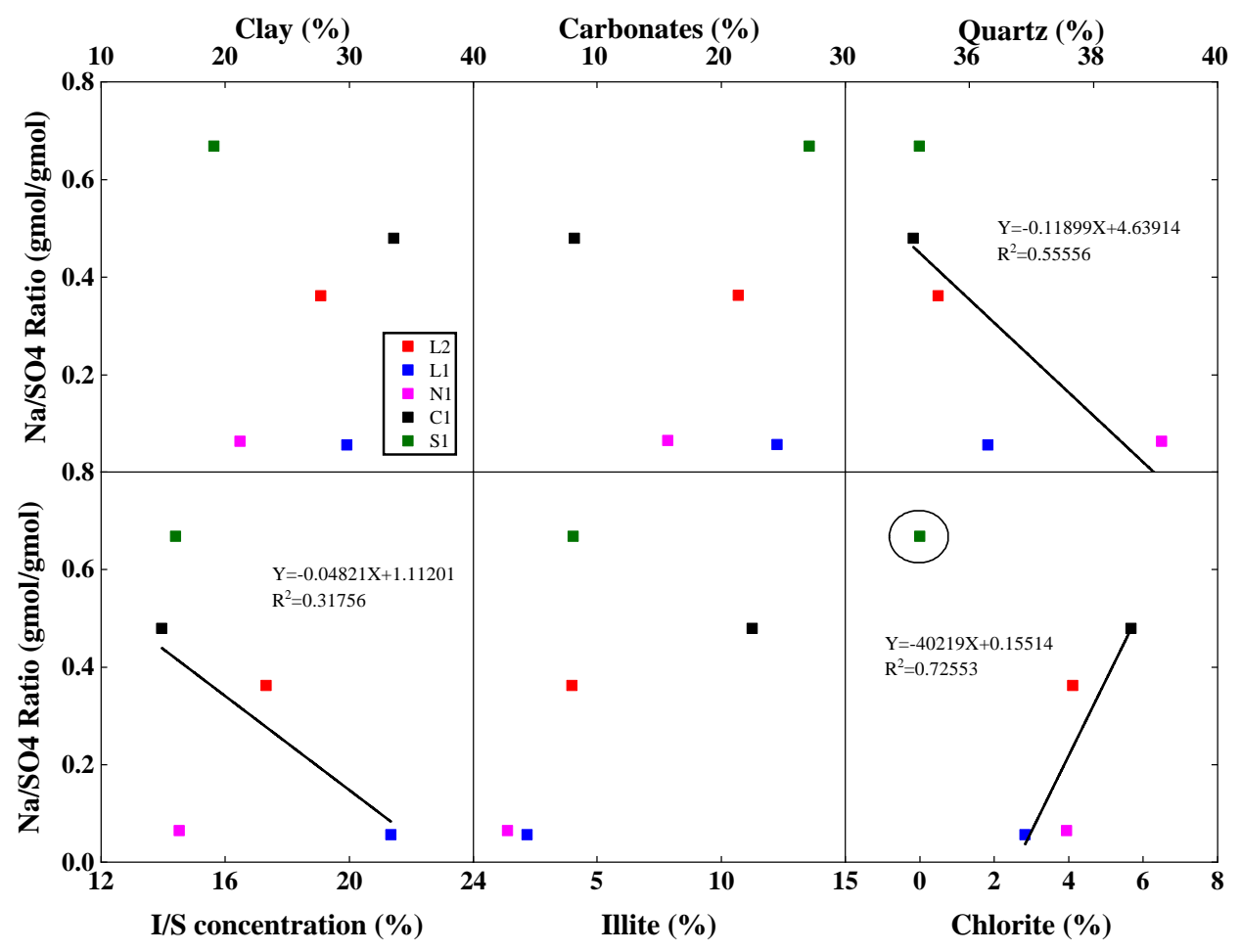

Fig. 15. The ions concentration and type in different formations. 
function. The water type of the shale and volcanic sample is continental water type, which is not conducive to oil and gas storage.

Fig. 13a shows the change in $\mathrm{Na}^{+} / \mathrm{Cl}^{-}$ratio for different formation samples. The values of $\mathrm{C} 1$ and $\mathrm{L} 1$ are the largest, and the value of $\mathrm{S} 1$ is the smallest. This may be related to the different mineral composition of formation samples. Fig. 14 shows the effect of different mineral content on $\mathrm{Na}^{+} / \mathrm{Cl}^{-}$ratio. The carbonate mineral content has a negative correlation with the $\mathrm{Na}^{+} / \mathrm{Cl}^{-}$ratio, while the clay mineral content has a good positive correlation with the $\mathrm{Na}^{+} / \mathrm{Cl}^{-}$ratio. As the content of clay minerals increases, the ratio of $\mathrm{Na}^{+} / \mathrm{Cl}^{-}$increases significantly, indicating that $\mathrm{NaCl}$ is likely to be mainly derived from clay minerals. The contents of illite and chlorite in clay minerals are positively correlated with the $\mathrm{Na}^{+} / \mathrm{Cl}^{-}$ratio, so the content of illite and chlorite is one of the key factors in determining the concentration of $\mathrm{NaCl}$. Because the clay particles themselves exhibit a pure electronegativity, which is compensated by the accumulation of a cation (diffusion layer) near the surface. Therefore, sodium ions on the surface can diffuse freely into the solution, and the movement of chloride ions is greatly restricted. However, the formation samples are rich in $\mathrm{I} / \mathrm{S}$ mixed minerals, so the samples produce more fractures during the spontaneous water imbibition. This result allows more chloride ions to enter the solution, making the $\mathrm{Na}^{+} / \mathrm{Cl}^{-}$ratio tend to balance. Judging from the change trend of the main ions in the solution, the $\mathrm{Na}^{+}, \mathrm{Cl}^{-}, \mathrm{Ca}^{2+}$, and $\mathrm{SO}_{4}^{2-}$ content in the solution is far greater than $\mathrm{Mg}^{2+}, \mathrm{Fe}^{2+}$ and other ions after a long time immersion. The results shows that a large amount of soluble salts in the shale are dissolved completely after 133 days immersion. At the same time, the soluble salts are mainly composed of sulfates and calcium salts, which are dissolved in the solution under a long-term immersion.

Although $\mathrm{Ca}^{2+}$ and $\mathrm{SO}_{4}^{2-}$ are the main ions, the concentration of $\mathrm{SO}_{4}^{2-}$ in all samples is higher than that of $\mathrm{Ca}^{2+}$ (Fig. 11). This indicates that $\mathrm{Na}_{2} \mathrm{SO}_{4}$ may also be present in the solution. Fig. $13 \mathrm{~b}$ shows the results of $\mathrm{Na}^{+} / \mathrm{SO}_{4}^{2-}$ ratio in different formation samples. The $\mathrm{Na}^{+} / \mathrm{SO}_{4}^{2-}$ ratio of $\mathrm{S} 1$ and $\mathrm{C} 1$ are the largest, and that of $\mathrm{L} 1$ and $\mathrm{N} 1$ solutions are the smallest. This may be related to the different mineral composition of formation samples. Fig. 15 shows the effect of different mineral contents on $\mathrm{Na}^{+} / \mathrm{SO}_{4}^{2-}$. The quartz mineral content has a negative correlation with the $\mathrm{Na}^{+} / \mathrm{SO}_{4}^{2-}$ ratio, and the illite and chlorite minerals content have a good positive correlation with the $\mathrm{Na}^{+} / \mathrm{Cl}^{-}$ratio. It can be seen that the $\mathrm{Na}^{+} / \mathrm{SO}_{4}^{2-}$ ratio is related to the total content of clay minerals and carbonate minerals. The illite and chlorite mineral may also be one of the main sources of $\mathrm{Na}_{2} \mathrm{SO}_{4}$.

\section{Conclusions}

In this experimental study, ion diffusion experiments are conducted on shale, volcanic rock and tight sandstone. The ion diffusion characteristics of different type ions and its influencing factors are further analyzed. The conclusions are as follows:

1) As the immersion time increases, the conductivity in the solution gradually increases. It shows that a large amount of salt ions dissolve and diffuse into the water, which improves the salinity of the water.

2) The larger the exposed area, the faster the solution conductivity rises. The high exposed area means that more salt-attached surfaces can come into contact with the solution, which can significantly increase the solution salinity. Therefore, the high complexity of the artificial fracture corresponds to the large exposed area and high salinity of the flow-back fluid.

3) The carbonate mineral content has an inverse correlation with the $\mathrm{Na}^{+} / \mathrm{Cl}^{-}$ratio, while the clay mineral content has a clear proportional relationship with the $\mathrm{Na}^{+} / \mathrm{Cl}^{-}$ ratio. The contents of illite and chlorite minerals have a positive correlation with the $\mathrm{Na}^{+} / \mathrm{Cl}^{-}$ratio, so the illite and chlorite minerals may be one of the key factors that determine the $\mathrm{Na}^{+} / \mathrm{Cl}^{-}$concentration.

\section{Acknowledgement}

The research is funded by National Natural Science Foundation of China (No. 11702296), and by the Fundamental Research Funds for the Central Universities (No. 2462019YJRC011).

\section{Conflict of interest}

The authors declare no competing interest.

Open Access This article, published at Yandy Scientific Press on behalf of the Division of Porous Flow, Hubei Province Society of Rock Mechanics and Engineering, is distributed under the terms and conditions of the Creative Commons Attribution (CC BY-NC-ND) license, which permits unrestricted use, distribution, and reproduction in any medium, provided the original work is properly cited.

\section{References}

Cai, J., Xia, Y., Lu, C., et al. Creeping microstructure and fractal permeability model of natural gas hydrate reservoir. Mar. Pet. Geol. 2020a, 115: 104282.

Cai, J., Xia, Y., Xu, S., et al. Advances in multiphase seepage characteristics of natural gas hydrate sediments. Chinese Journal of Theoretical and Applied Mechanics 2020b, 52(1): 208-223. (in Chinese)

Cheng, C., Perfect, E., Donnelly, B., et al. Rapid imbibition of water in fractures within unsaturated sedimentary rock. Adv. Water Resour. 2015, 77: 82-89.

Fakcharoenphol, P., Kazemi, H., Charoenwongsa, S., et al. The effect of osmotic pressure on improve oil recovery from fractured shale formations. Paper SPE 168998 Presented at SPE Unconventional Resources Conference, The Woodlands, Texas, USA, 1-3 April, 2014.

Gdanski, R.D., Fulton, D.D., Johnson, B.J. Returns matching reveals new tools for fracture/reservoir evaluation. Paper SPE 133806 Presented at Tight Gas Completions Conference, San Antonio, Texas, USA, 2-3 November, 2010.

Ghanbari, E., Abbasi, M.A., Dehghanpour, H., et al. Flowback volumetric and chemical analysis for evaluating load 
recovery and its impact on early-time production. Paper SPE 167165 Presented at SPE Unconventional Resources Conference Canada, Calgary, Alberta, Canada, 5-7 November, 2013.

Haluszczak, L.O., Rose, A.W., Kump, L.R. Geochemical evaluation of flowback brine from Marcellus gas wells in Pennsylvania, USA. Appl. Geochem. 2013, 28: 55-61.

Li, J., Li, X., Wang, X., et al. Water distribution characteristic and effect on methane adsorption capacity in shale clay. Int. J. Coal Geol. 2016, 159: 135-154.

Li, S., Hou, S. A brief review of the correlation between electrical properties and wetting behaviour in porous media. Capillarity 2019, 2(3): 53-56.

Mahabadi, N., Zheng, X., Jang, J. The effect of hydrate saturation on water retention curves in hydratebearing sediments. Geophys. Res. Lett. 2016, 43(9): 4279-4287.

Meng, M., Ge, H., Ji, W., et al. Research on the auto removal mechanism of shale aqueous phase trapping using low field nuclear magnetic resonance technique. J. Pet. Sci. Eng. 2016, 137: 63-73.

Sun, Y., Lu, H., Lu, C., et al. Hydrate dissociation induced by gas diffusion from pore water to drilling fluid in a cold wellbore. Adv. Geo-Energy Res. 2018, 2(4): 410-417.

Tao, Z., Zhao, F., Wang, H., et al. Innovative constant resistance large deformation bolt for rock support in high stressed rock mass. Arab. J. Geosci. 2017, 10(15): 341.

Yang, L., Ge, H., Shi, X., et al. Experimental and numerical study on the relationship between water imbibition and salt ion diffusion in fractured shale reservoirs. J. Nat. Gas Sci. Eng. 2017a, 38: 283-297.

Yang, L., Shi, X., Ge, H., et al. Quantitative investigation on the characteristics of ions transport into water in gas shale: Marine and continental shale as comparative study. J. Nat. Gas Sci. Eng. 2017b, 46: 251-264. 